\title{
Evaluation of Knowledge, Attitude and Practices of Resident Doctors, Interns and Nurses on Adverse Drug Reaction Monitoring and Reporting In a Tertiary Care Hospital
}

\author{
Authors \\ Rohini P.Jagtap ${ }^{1}$, Rajesh R.Todkar ${ }^{2}$, Kalpita G.Gawit ${ }^{3}$, Balasaheb B.Ghongane ${ }^{4}$ \\ ${ }^{1}$ Associate Professor, Dept. of Pharmacology, B. J. Govt Medical College and SGH Pune, India-411001 \\ Email:drrohinijagtap@gmail.com \\ 2,3 Junior resident, Dept. of Pharmacology, B. J. Government Medical College and SGH Pune, India-411001 \\ ${ }^{4}$ Professor and Head, Dept. of Pharmacology, B. J. Govt Medical College and SGH Pune, India-411001 \\ Email: ghongane.bb@gmail.com
}

Corresponding Author

Rajesh Ramkishan Todkar

Email: dr.rajeshtodkar007@gmail.com, 9423583490

\begin{abstract}
Objective:- To assess the knowledge, attitude and practices regarding adverse drug reaction (ADR) reporting as well as to evaluate the barriers involved in non-reporting of suspected ADRs in Resident doctors, Interns and Nurses at tertiary care hospital.

Methods: A prospective, cross sectional, questionnaire based study was conducted in 158 Interns ,75 Resident doctors and 60 Nurses at a tertiary care hospital during March-June 2016. The questionnaire was used to assess their knowledge, attitude and practices regarding adverse drug reaction reporting. A questionnaire comprising of 20 questions was distributed to interns, resident doctors and nurses.

Result: $83 \%$ interns, $88 \%$ resident doctors and $50 \%$ nurses were aware about the definition of adverse drug reactions and $60 \%$ interns, $73 \%$ resident doctors and $53 \%$ nurses had come across adverse drug reaction but they had not reported ADR because they did not know how and where to report suspected ADR and they were afraid of damage to their professional image and thought they may land up into legal issues. $55 \%$ participants had shared the information regarding ADRs with senior physicians but they had not received training on ADR reporting in their curriculum. 96.5\% interns, $72 \%$ resident doctors and $88.93 \%$ nurses opined that to improve the ADR reporting, it is essential to conduct pharmacovigilance workshops and seminars.

Conclusion: The results of the study show that there is a need to create awareness in interns, resident doctors and nurses regarding suspected ADR reporting. Factors discouraging reporting of suspected ADR can be overcome by appropriate educational interventions. There is a need for regular training and reinforcement of guidelines for ADR reporting among health care personnel.

Keywords: Adverse drug reaction; Attitude; Knowledge; Practices; Barriers.
\end{abstract}

\section{INTRODUCTION}

Effective reporting of adverse drug reactions
(ADRs) is an important mechanism for postmarketing surveillance of medicines and is vital for 
maintaining drug safety. It is crucial that healthcare professionals remain vigilant, are aware of the need to report and keep track of any changes to the systems in place [1] Now a day, there is an explosion of information regarding the availability and use of non-prescription drugs that can be bought over the counter (OTC). The OTC drugs include not only the allopathic drugs, but also the drugs from allied pathies eg.herbal medicines etc., which hardly show evidence based proofs. Polypharmacy also precipitates the issue of ADRs making it difficult to identify and assign the ADR to a particular drug. So high index of suspicion is very important on the part of healthcare professionals.

Safety monitoring of medicines is an essential element of healthcare for provision of high-quality medical care.ADRs have a major impact on public health because of considerable economic burden on the society. ${ }^{2}$ It is estimated that only $6-10 \%$ of ADRs are reported worldwide. ${ }^{[3]}$ A study showed that hospital admissions due to ADRs accounted for $0.7 \%$ of total admissions and deaths due to ADRs accounted for $1.8 \%$ of total admissions in a territory referral center in South India. ${ }^{[4]}$ The safety of patients and the safe use of medicines are high priorities in the modern world. The first practical international co-operation in drug monitoring started in 1968. The ideas came up as a consequence of the so-called thalidomide tragedy. [5] In the 1960s, it was discovered limb deformities in babies may occur if thalidomide, ingested by mothers during pregnancy. This incident became the modern starting point of a science focusing on patient problems caused by the use of medicines.

Adverse drug reaction (ADR) is defined as "a response to a drug, which is noxious and unintended, and which occurs at doses normally used in man for the prophylaxis, diagnosis or therapy of disease or for the modification of physiological function" ${ }^{[6]}$. ADRs are one of the major health care problems occurring throughout the world. They affect the people with varying magnitudes, causing both morbidity and mortality. ${ }^{[7,8]}$
Pharmacovigilance is the science and activities related to the detection, assessment, understanding, and prevention of adverse effects or any other possible drug-related problems. ${ }^{9]}$ To transform the concept of pharmacovigilance into practice for enhancing the safety of patients, ADR monitoring centres (AMCs) are being set up across the country under pharmacovigilance programme of India (PvPI). ${ }^{[10]}$ The contribution of health professionals is enormous in this regard. However, underreporting still remains a major obstacle in the complete success of pharmacovigilance program ${ }^{[11]}$.

High rate of underreporting is a matter of great concern which can delay detection of serious ADRs and consequently have a major negative impact on the public health. It is important to monitor every undesirable effect of medicines in order to determine any new information available in relation to their safety profile. In a large country like India with ethnic variability, different disease prevalence patterns, practice of different systems of medicines, different socioeconomic strata and status, it is important to have a standardized and robust pharmacovigilance and drug safety monitoring programme for the nation. Collection of this information and analysis of this data can be useful to reach to a meaningful conclusion on the continued use of these medicines is the rationale of pharmacovigilance. The results thus obtained will be useful in changing the labelling of medicines indicating restriction in use or issue of statutory warning, precautions, or even withdrawal of the drug from the market. This also helps in educating doctors about ADRs and in the official regulations of drug.

Spontaneous reporting is the core data-generating system of international pharmacovigilance, relying on healthcare professionals (and in some places consumers) to identify and report any suspected ADRs to their national pharmacovigilance centre or to the manufacturer. Spontaneous reports are almost always submitted voluntarily. However, reporting of serious ADRs rarely exceeds $10 \%$ though the figures vary greatly between countries and in relation to minor and serious ADRs. Overall underreporting of ADRs is a common problem in pharmacovigilance 
programs ${ }^{[11]}$. To reinforce the importance of pharmacovigilance and the reporting of ADRs is very important but over worked medical personnel does not always see reporting as a priority. If the symptoms are not serious, they may not notice them at all. And even if the symptoms are serious, they may not be recognized as the effect of a particular drug. After observing the Pharmacovigilance programme of our institution we found that the problems of underreporting and lack of awareness were prevalent in the community of health professionals.

It is observed that Nurses play a very important source of possible ADR alerts to the clinicians. ${ }^{[12]}$ Taking into consideration all these factors,we planned to conduct a study to know the awareness of Pharmacovigilance among health care professionals of our institute.

\section{AIMS AND OBJECTIVES OF THE STUDY}

1. To assess the awareness of pharmacovigilance.

2. To determine the major barriers and to identify the factors that prohibit the implementation of a ADR reporting

3. To find out the gaps identified by the various researchers and make recommenddations for effective pharmacovigilance

\section{MATERIAL \& METHODS}

Study Design: It was a randomised, cross sectional, observational, questionnaire-based study.

The Study Setting: It was conducted at a 1200bedded tertiary care teaching hospital in Pune, Maharashtra. This questionnaire survey was conducted during March -June 2016 and approval from Institutional Ethical Committee was obtained prior to administering the questionnaire survey.

Study Population: Residents from all specialties working in the hospital which have the potential of adverse drug reactions were enrolled in the study. Those who were not willing to participate or did not return the questionnaire within the stipulated time were excluded.

Questionnaire was designed to capture the following information: specialties and designation of health care professional. Study was carried out in resident doctors, nursing staff and interns working in the tertiary care hospital. Provision was also made for suggestions through open ended questions. Small changes in the order and phrasing of the questions were made after a pilot study. Knowledge, attitude and practices ( KAP )questionnaire containing 20 questions (knowledge 12, attitude 4, and practice 4) was designed using the precedence set by similar studies to obtain information regarding knowledge , attitude and practice of ADR reporting and the factors that encouraged and discouraged reporting along with suggestions to improve ADR reporting, was designed .The questionnaire was pre-tested in ten postgraduate students and ten faculties and a suitably modified version was finally administered to the willing respondents It was prevalidated to identify any potential bias errors.

The questionnaire was administered to the resident doctors, interns and nurses in all the clinical wards, outpatient departments and postgraduate programme clinics according to their convenience. All participants were requested to complete the questionnaire and hand it back immediately, to maximize the response rate.

\section{STATISTICAL ANALYSIS}

The completed questionnaire information was recorded using Microsoft Excel sheet and percentages of responses were calculated.

\section{RESULTS}

The questionnaire was administered to 400 health professionals but only $293(77.25 \%)$ returned and responded to it. The response rates were $79 \%$ among interns, $75 \%$ among resident doctors and 60 $\%$ were among nurses. Awareness about pharmacovigilance based on our assumption of response to question number 20 of the questionnaire was calculated. It was $91 \%$ among interns, $86 \%$ among resident doctors, $65 \%$ in nurses. We did not include the responses of unaware respondents in further statistical analysis of questionnaire 
Diagram 1: Sources of information regarding Adverse Drug reactions.

\section{SOURCE OF INFORMATION}

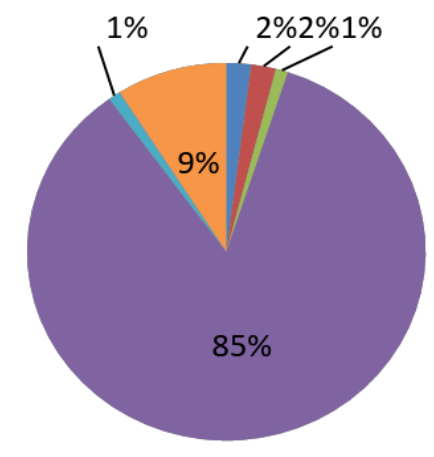

Table 2 : shows attitudes of nurses, interns and the resident doctors regarding adverse event reporting. Table 2 reveals that the reasons for underreporting by interns, nurses and the resident doctors were different. Lack of time to report ADR was the main reason given by residents (22\%) and not knowing to whom and where to report was the main reason given by Interns $(82 \%) .99 .05 \%$ interns think that reporting of adverse drug reaction is necessary compared to $92 \%$ and $95 \%$ of the resident doctors and nurses respectively. ADR reporting should be compulsory according to $65 \%$ of interns compared to $76 \%$ and $65 \%$ of the resident doctors and nurses respectively.96\% of interns thought that Pharmacovigilance workshop should be conducted for the healthcare professionals while $72 \%$ and $88 \%$ of the resident doctors and nurses as this is important.

Table 2 : Attitude of Interns, Resident doctors and Nurses regarding adverse drug reaction monitoring and reporting.

Table 1: Reveals knowledge or awareness regarding ADR monitoring and reporting.It shows that awareness about location of pharmacovigilance centre was $32 \%$ in interns, $28 \%$ in resident doctors and16\% in nursing staff. Likewise, $69 \%$ interns ,72\% resident doctors and $46 \%$ nurses were aware about banned drugs in recent past. 91 $\%$ interns, $86 \%$ resident doctors and $65 \%$ nurses were awareness about aims of pharmacovigilance while $96 \%$ interns, $88 \%$ residents doctors and $55 \%$ gave correct response to definition of adverse drug reaction.

Table No. 1- Assessment of knowledge about adverse drug reactions among, Interns ,Resident doctors and Nurses.

\begin{tabular}{|l|c|c|c|c|}
\hline $\begin{array}{l}\text { Nurses } \\
(\mathbf{n}=60)\end{array}$ & $\begin{array}{c}\text { Resident } \\
\text { Doctors } \\
(\mathbf{n = 7 5}) \\
\%\end{array}$ & $\begin{array}{c}\text { Intern } \\
\mathbf{s} \\
(\mathbf{n}=158 \\
)\end{array}$ & Answers & Questions \\
\hline 55 & $\mathbf{8 8}$ & 96 & Correct & $\begin{array}{c}\text { 1. What is adverse drug } \\
\text { reaction? }\end{array}$ \\
\hline 65 & 86 & 91 & Correct & $\begin{array}{c}\text { 2. Aims of } \\
\text { pharmacovigilance? }\end{array}$ \\
\hline 16 & 28 & 32 & Correct & $\begin{array}{c}\text { 3.Location of national PV } \\
\text { centre? }\end{array}$ \\
\hline 39 & 74 & 36 & Yes & $\begin{array}{c}\text { 4.ADR form availability } \\
\text { at institute ? }\end{array}$ \\
\hline 56 & 64 & 68 & Correct & $\begin{array}{c}\text { 5. In your opinion, which } \\
\text { of the following products } \\
\text { should to be monitored } \\
\text { for ADRs? }\end{array}$ \\
\hline 46 & 72 & 69 & Yes & $\begin{array}{c}\text { 6.Are you aware of any } \\
\text { drug that has been } \\
\text { banned in the recent } \\
\text { past? }\end{array}$ \\
\hline
\end{tabular}

\begin{tabular}{|c|c|c|c|c|}
\hline $\begin{array}{l}\text { Nurses } \\
(\mathrm{n}=60) \\
\%\end{array}$ & $\begin{array}{c}\text { Resident } \\
\text { Doctors } \\
(n=75) \\
\%\end{array}$ & $\begin{array}{c}\text { Interns } \\
(\mathrm{n}=158) \\
\%\end{array}$ & & Questions \\
\hline 6 & 13 & 5 & Legal issues & \multirow[t]{3}{*}{$\begin{array}{c}\text { Factors discouraging } \\
\text { the reporting }\end{array}$} \\
\hline 75 & 72 & 82 & $\begin{array}{l}\text { Not knowing } \\
\text { where and how } \\
\text { to report }\end{array}$ & \\
\hline 15 & 8 & 3 & $\begin{array}{l}\text { Not knowing } \\
\text { importance }\end{array}$ & \\
\hline 95 & 92 & 99 & & $\begin{array}{c}\text { Do you feel it is } \\
\text { necessary to report } \\
\text { an ADR? }\end{array}$ \\
\hline 8 & 8 & 2 & Voluntary & \multirow{3}{*}{$\begin{array}{l}\text { ADR reporting } \\
\text { should be }\end{array}$} \\
\hline 65 & 76 & 65 & Mandatory & \\
\hline 16 & 13 & 33 & Need based & \\
\hline 88.93 & 72 & 96 & Yes & $\begin{array}{c}\text { Do you think } \\
\text { workshop on } \\
\text { pharmacovigilance } \\
\text { will improve } \\
\text { reporting? }\end{array}$ \\
\hline
\end{tabular}

Diagram 2: Barriers for Non Reporting ADRs in Interns

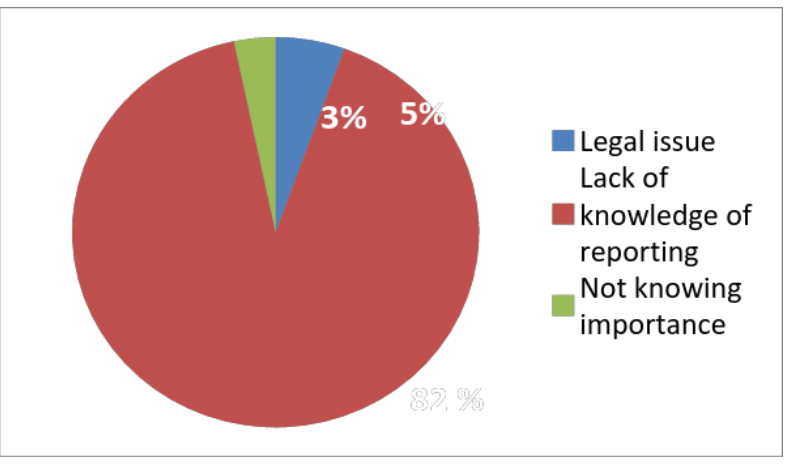




\section{JMSCR Vol||05||Issue||03||Page 19052-19059||March}

Table 3: Reveals that about $60 \%$ interns, $73 \%$ resident doctors and $53 \%$ nurses came across an ADR. 82.27\% interns had not reported ADR because they did not know how and where to report suspected ADR. 52\% of interns, $46 \%$ resident doctors and $35 \%$ nurses were of the opinion that an ADR should be mentioned on patients case record.65\% interns, $51 \%$ resident doctors and $81 \%$ nurses had reported all types of adverse drug reactions i.e. Mild, moderate and severe. It was observed that main barrier for reporting of adverse drug reaction was lack of knowledge of how and where to report adverse drug reaction.

Tables 3- Practices of Interns, Resident doctors and Nurses regarding adverse drug reaction reporting

\begin{tabular}{|c|c|c|c|c|}
\hline $\begin{array}{l}\text { Nurses } \\
(n=60) \%\end{array}$ & $\begin{array}{c}\text { Resident } \\
\text { Doctors } \\
(n=75) \% \\
\end{array}$ & $\begin{array}{c}\text { Interns } \\
(\mathrm{n}=158) \%\end{array}$ & & Questions \\
\hline 53 & 73 & 60 & yes & $\begin{array}{l}\text { Have you } \\
\text { come across } \\
\text { any ADR / } \\
\text { ADRs? }\end{array}$ \\
\hline $\mathbf{0}$ & 3 & 55 & $\begin{array}{l}\text { Ask the } \\
\text { patients }\end{array}$ & \multirow{5}{*}{$\begin{array}{l}\text { How will } \\
\text { you find out } \\
\text { ADRs? }\end{array}$} \\
\hline $\mathbf{0}$ & 3 & 4 & $\begin{array}{l}\text { Patient self- } \\
\text { reporting }\end{array}$ & \\
\hline $\mathbf{0}$ & 16 & 10 & $\begin{array}{c}\text { Ask the patient } \\
\text { relatives }\end{array}$ & \\
\hline 6 & 4 & 5 & $\begin{array}{c}\text { monitor the } \\
\text { patient reports }\end{array}$ & \\
\hline 68 & 72 & 65 & All the above & \\
\hline 35 & 46 & 52 & always & \multirow{4}{*}{$\begin{array}{l}\text { Do you } \\
\text { mention the } \\
\text { ADRs on } \\
\text { the patient's } \\
\text { case record } \\
\text { if } \\
\text { encountered } \\
\text { ? }\end{array}$} \\
\hline 13 & 44 & 3 & sometimes & \\
\hline 6 & $\mathbf{0}$ & 7 & never & \\
\hline 6 & 10 & 3 & $\begin{array}{c}\text { managed } \\
\text { without } \\
\text { reporting }\end{array}$ & \\
\hline 3.3 & 2.6 & 2 & Minor & \multirow{4}{*}{$\begin{array}{l}\text { Which } \\
\text { severity do } \\
\text { you report? }\end{array}$} \\
\hline 10 & 16 & 9.5 & Moderate & \\
\hline 6.6 & 28 & 12 & Severe & \\
\hline 81 & 50.66 & 65 & All the above & \\
\hline
\end{tabular}

\section{DISCUSSION}

Reporting of ADR is an essential component of pharmacovigilance. At any given time, postmarketing surveillance should be in place. Many studies have evaluated the knowledge of healthcare professionals about Pharmacovigilance. In our study, majority of healthcare professionals thought that ADR reporting should be mandatory, this shows the sense of responsibility on their part. $82 \%$ interns, $72 \%$ of resident doctors, $75 \%$ nurses have said that the reason for nonreporting was inadequate knowledge regarding the location and the procedure of ADR reporting.A 1976 discussion by Dr Bill Inman, who pioneered the Yellow Card Scheme, highlighted 'Seven deadly sins' that might cause the low reporting rate of ADRs among healthcare professionals. ${ }^{[13]}$ One survey of UK healthcare professionals showed that the only 'sin' still affecting reporting of ADRs was 'lethargy' [14] We think, it may not be lethargy, but the 'time constraint' which may be preventing them from reporting ADRs. This is a well-known fact that doctors and other healthcare professionals are very busy catering to the needs of the patients.

In our study, the response rate of participants was $73.25 \%$ which is similar to that shown by Desai et al who reported a response rate of $70.7 \%$ in resident doctors [15] ADRs contribute significantly to morbidity and mortality in clinical practice with its associated economic consequences ${ }^{[16] . ~ S t u d i e s ~ f r o m ~}$ developed economies such as UK and USA have reported a higher rate of ADR reporting and higher awareness among healthcare professionals about pharmacovigilance ${ }^{[17,18]}$. while current contribution of India to global safety database is 3\% [19] In our study, the perception is high which is similar to study from India which has reported encouraging findings regarding attitudes and perceptions of medical practitioners about pharmacovigilance ${ }^{\text {[20] }}$

Spontaneous ADR reporting is a vital method for detecting new safety issues related to drugs.But reporting the same exclusively in resident doctors was observed in very few studies. Many studies from India as well as other countries have reported lower rates of ADR reporting and awareness among healthcare professionals about pharmacovigilance [21]. Nurses could be a useful resource for improving the reporting rate of ADRs .This finding was supported by other studies also. ${ }^{[22]}$ The paramedical staff could play an important role in ADRs reporting, because they are close to the patient and are responsible for drug administration and recording side effects. They can alert the responsible physician about possible ADRs without time gap. Thus it is crucial to encourage the paramedical staff towards ADR reporting ${ }^{[23]}$ 
Our study has shown optimum knowledge of interns and the resident doctors about ADRs but not of nurses. The practice of reporting was inadequate in all health professionals. A major part of respondents have come across ADRs but they did not report it because of many barriers in ADRs reporting as shown in the pie chart no.1. This emphasizes the need for training in pharmacovigilance. In our study,various strategic approaches suggested by the respondents to improve ADR reporting are initiation of workshop on ADR reporting and monitoring for health care professionals, including ADR reporting in curriculum of undergraduate \& postgraduate students and nurses, as well as developing quick response/ rapid action team for reporting ADR at hospital level.

We thought that a visit to a pharmacovigilance centre and observation of its functioning will give a great insight to the practical knowledge of ADR reporting. In addition to contributing to the safety profiles of existing drugs, pharmacovigilance activities help to improve the knowledge set and contribute to the breadth of epidemiological data. ${ }^{[1]}$ Inappropriate prescribing and polypharmacy should be avoided. ${ }^{[24]}$ Training sessions to clarify the role of various healthcare professionals in pharmacovigilance, to address the various perceived obstacles and to spontaneous reporting, will hopefully fill the observed gaps in knowledge and practices.

\section{CONCLUSION}

In conclusion, our study strongly suggests that there is a great need to create awareness and to promote the reporting of ADR amongst interns and doctors, which will lay a solid foundation for these healthcare professionals to be diligently involved in quality pharmacovigilance in their future practices. Attitudinal and cultural changes, whereby ADR reporting is seen as an integral part of the clinical activities of the doctors, are very necessary for a long term improvement of ADR reporting. A thorough knowledge of ADRs and a wellestablished ADRs reporting system will help to reduce the occurrence and the costs of avoidable ADRs related admissions. We recommend that several such studies of similar kind should be conducted among other institutions so as to develop strategies to improve and strengthen the pharmacovigilance in India.

ADR reporting should be intensively taught during undergraduate study, and this should be reinforced at the start of internships as well as periodically thereafter through continuous education programs. Effective pharmacovigilance should take into account trends in use of drugs as well as the occurrence of ADRs, enabling more effective advice to be given to those prescribing and using medications and should ensure better standards of safety and efficacy. The pharmacovigilance systems in the India are in infancy but now started gaining momentum and present excellent opportunities for generating signals about potential drug hazards ${ }^{[29]}$. These systems can only be successful, when utilised effectively and if awareness of their importance is continually highlighted.

\section{ACKNOWLEDGEMENT}

We would like to thank the resident doctors, interns and nurses who participated in the study.

\section{Conflict of Interest}

The authors declare no conflict of interest

\section{REFERENCES}

1. British Medical Association. Reporting adverse drug reactions: a guide for healthcare professionals. In Reporting adverse drug reactions: a guide for healthcare professionals 2006 May.Available from http://www.isoponline.org/wpcontent/uploads/2015/01/BMAreport.pdf accessed on 25/03/17

2. Oshikoya KA, Awobusuyi JO. Perceptions of doctors to adverse drug reaction reporting in a teaching hospital in Lagos, Nigeria. BMC clinical pharmacology. 2009 Dec 1;9(1):14.

3. World Health Organization. The importance of pharmacovigilance.2002 available from 
http://apps.who.int/medicinedocs/pdf/s4893 e/s4893e.pdf accessed on 25/03/2017

4. Ramesh M, Pandit J, Parthasarathi G. Adverse drug reactionsin a south Indian hospital - Their severity and cost involved. Pharmacoepidemiol Drug Saf 2003;12: 687-92.

5. Reddy VL, Pasha SJ, Rathinavelu M, Reddy YP. Assessment of knowledge, attitude and perception of pharmacovigilance and adverse drug reaction (ADR) reporting among the pharmacy students in south India. IOSR J Pharm Biol Sci. 2014;9(2):34-43.

6. World Health Organization. International drug monitoring: the role of national centres, report of a WHO meeting [held in Geneva from 20 to 25 September 1971]. Available from https://www.whoumc.org/media/2680/who-technical-report498.pdf Accessed on 01/03/27

7. Pirmohamed M, James S, Meakin S, Green C, Scott AK, Walley TJ, Farrar K, Park BK, Breckenridge AM. Adverse drug reactions as cause of admission to hospital: prospective analysis of 18820 patients. Bmj. 2004 Jul 1;329(7456):15-9.

8. Lazarou J, Pomeranz BH, Corey PN. Incidence of adverse drug reactions in hospitalized patients: a meta-analysis of prospective studies. JAMA. 1998 Apr 15;279(15):1200-5.

9. The importance of pharmacovigilance. Safety monitoring of medicinal products. Geneva: World Health Organization; World Health Organization Collaborating Centre for International Drug Monitoring; 2002

10. Pharmacovigilance programme of India 2010. CDSCO, Ministry of Health and Family Welfare, Government of India; 2010.available

from http://www.cdsco.nic.in/forms/contentpage 1. aspx ?lid=1752 accessed on 05/03/17

11. Lopez-Gonzalez E, Herdeiro MT, Figueiras A. Determinants of under-reporting of adverse drug reactions. Drug safety. 2009 Jan 1;32(1):19-31.

12. Ulfvarson J, Mejyr S, Bergman U. Nurses are increasingly involved in pharmacovigilance in Sweden. Pharmacoepidemiology and drug safety. 2007 May 1;16(5):532-7.

13. Inman WHW,Assessment drug safety problems. In: Gent M, Shigmatsu I, editors. Epidemiological issues in reported druginduced illnesses. Honolulu, Ontario: McMaster University Library Press; 1976. p. 17-24

14. Belton K, Lewis S \& Payne $S$ et al Attitudinal survey of adverse drug reaction reporting by medical practitioners in the United Kingdom. British Journal of Clinical Pharmacology 1995: 39 : 223-6.

15. Desai CK, Iyer G, Panchal J, Shah S, Dikshit RK An evaluation of knowledge, attitude, and practice of adverse drug reaction reporting among prescribers at a tertiary care hospital. Perspect Clin Res 2011 :2: 129-136

16. Pimpalkhute SA, Jaiswal KM, Suntakke SD, Bajait CS, Gaikwad A. Evaluation of a awareness about pharmacovigilance and adverse dryg reaction monitoring in resident doctors of a tertiary care teaching hospital. Indian J Med Sci 2012; 66:55-61).

17. Bateman DN, Sanders GL, Rawlins MD. Attitudes to adverse drug reaction reporting in the Northern Region. Br J Clin Pharmacol. 1992;34:421-6.

18. Milstein JB, Faich GA, Hsu JP. Factors affecting physician reporting of adverse drug reactions. Drug Inf J. 1986;20:157-64.

19. Vivekanandan Kalaiselvan, Prasad Thota, Gyanendra Nath Singh' Pharmacovigilance Programme of India: Recent developments and future perspectives, Indian Journal of Pharmacology Year: 2016, Volume : 48, Issue : 6,Page : 624-628

20. Ramesh M, Parthasarathi G :Adverse drug reactions reporting: attitudes and perceptions of medical practitioners. Asian J Pharm Clin Res 2009:2: 10-4.) 
21. Hazell L, Shakir SA. Under-reporting of adverse drug reactions: A systematic review. Drug Saf. 2006;29:385-96.

22. Morrison-Griffiths S, Walley T \& Park B et al ,Reporting of adverse drug reactions by nurses. The Lancet :2003 361:1347.

23. Bäckström M, Ekman E, Mjörndal T Adverse drug reaction reporting by nurses in Sweden. Eur J Clin Pharmacol,2007: 63: 613-618.

24. Lavan AH, Gallagher P. Predicting risk of adverse drug reactions in older adults. Therapeutic advances in drug safety. 2016 Feb;7(1):11-22. 